\title{
Somatosensory Evoked Potential and Brain Water Content in Post-Asphyxic Immature Piglets
}

\author{
VICKI C. ROSE, DONALD H. SHAFFNER, CHRISTINE A. GLEASON, RAYMOND C. KOEHLER, \\ AND RICHARD J. TRAYSTMAN \\ Departments of Pediatrics [V.C.R., D.H.S., C.A.G.] and Anesthesiology/Critical Care Medicine \\ [D.H.S, R.C.K., R.J.T.], The Johns Hopkins Medical Institutions, Baltimore, Maryland 21287-4961
} \begin{abstract}
Depression of somatosensory evoked potentials (SEP) after a
single episode of complete asphyxia with near cardiac arrest was evaluated to determine whether persistent SEP depression is related to postresuscitation edema in cortical gray matter or subcortical white matter. Piglets $(<7 \mathrm{~d}$ of age) were anesthetized with sodium pentobarbital and fentanyl. Asphyxia was produced by occlusion of the endotracheal tube for $7 \mathrm{~min}$. Arterial $\mathrm{O}_{2}$ saturation fell to $5 \%$. Resuscitation was achieved in $<2$ min with ventilation, epinephrine, and chest compressions. Regional brain water content was determined from the difference between wet and dry weight. Two control groups were also analyzed; one immediately after $(n=5)$ and one $6 \mathrm{~h}$ after induction $(n=7)$ of anesthesia. SEP amplitude became isoelectric during asphyxia and recovered to $50 \pm 13 \%(n=7)$ of baseline $6 \mathrm{~h}$ after resuscitation. In the 6-h control group, SEP amplitude remained
\end{abstract}

Perinatal asphyxia can cause regional brain injury detectable by magnetic resonance imaging (1). Acute cerebral edema, a consequence of perinatal asphyxia, may be associated with neurologic injury, although the mechanisms remain unclear. If the severity of injury is sufficiently severe to cause loss of ion homeostasis, edema would be anticipated in gray or white matter. Cerebral edema may be detected as early as $30 \mathrm{~min}$ after hypoxic-ischemic injury (2).

SEP are indicators of neurotransmission function of somatosensory gray matter and subcortical white matter tracts, areas often injured during asphyxia or hypoxia. Depressed SEP amplitude may be associated with impaired cortical neuronal generators of evoked potentials. During the onset of ischemia or severe hypoxemia, alterations in SEP occur at critically low levels of cerebral blood flow and oxygen delivery $(3,4)$ that correlate with inability to maintain cerebral oxygen consumption $(5,6)$. In addition to being a sensitive indicator of anoxia in somatosensory cortex, SEP is also influenced by subcortical

Received September 22, 1993; accepted December 18, 1994.

Correspondence: Raymond C. Koehler, Ph.D., Department of Anesthesiology/CCM, The Johns Hopkins University, Blalock 1408, 600 N. Wolfe Street, Baltimore, MD 21287-4961.

Supported by a grant from the National Institutes of Health (PO1 NS20020). above baseline. The percent water content (mean \pm SEM) among the three groups (asphyxia versus time control versus brief anesthesia control) was not different in the cortical gray matter $(83.0 \pm 0.7 \%$ versus $82.4 \pm 0.4 \%$ versus $83.2 \pm 0.3 \%)$ or subcortical white matter $(75.6 \pm 0.8 \%$ versus $74.8 \pm 0.9 \%$ versus $75.6 \pm 0.5 \%$ ). In seven other piglets, cerebral blood flow and $\mathrm{O}_{2}$ consumption recovered to baseline by $1 \mathrm{~h}$ after asphyxia. Therefore, we found that the sustained depression of SEP amplitude, after $7 \mathrm{~min}$ of asphyxia in immature piglets, is not related to brain edema or persistent decreases in global cerebral $\mathrm{O}_{2}$ consumption. (Pediatr Res 37: 661-666, 1995)
Abbreviation
SEP, somatosensory evoked potential

white matter conduction. With moderate forebrain ischemia, decreases in white matter blood flow and energy metabolism can precede those in gray matter and affect SEP $(7,8)$. With focal cerebral ischemia, some regions of somatosensory cortex can have near-normal levels of blood flow but have depressed SEP associated with subcortical white matter ischemia (9-11). During reperfusion and reoxygenation, recovery of SEP depends on the severity, duration, and location of reduced blood flow (12-14). Slow recovery of energy metabolism is associated with poor SEP recovery $(13,15)$. Moreover, after severe incomplete or complete cerebral ischemia, piglets have fuller recovery of SEP and cerebral $\mathrm{O}_{2}$ consumption compared with more mature pigs $(16,17)$.

Poor SEP recovery is also associated with poor resolution of edema in cortical gray matter and subcortical white matter (11). Although edema, per se, may not be responsible for depressed SEP, edema may be a marker of inadequate energy metabolism and ionic homeostasis necessary for neurotransmission. Therefore, we postulated that impaired recovery of SEP after an asphyxic event would correlate with persistent edema in gray matter and white matter and with impaired recovery of oxidative metabolism. The interrelationship of SEP and resolution of edema has not been well investigated in a newborn model of asphyxia. 
In the present study, we evaluated the effect of complete asphyxia in immature piglets on regional brain water content and recovery of SEP and cerebral oxygen consumption. The purpose was to determine whether the delayed recovery of SEP amplitude after asphyxia, with near cardiac arrest and successful resuscitation, is associated with the acute onset of cerebral edema in cortical gray matter or subcortical white matter.

\section{METHODS}

Surgical preparation. All surgical and experimental protocols were approved by the institutional Animal Care and Use Committee. Brain water content was measured in 19 piglets (1-6 d old; $1.7-3.8 \mathrm{~kg}$ ) divided into three groups: group 1, asphyxia $(n=7)$; group 2, 6-h control $(n=7)$; group 3, brief anesthesia control $(n=5)$. In a fourth group $(n=7)$, cerebral blood flow and $\mathrm{O}_{2}$ consumption were measured after asphyxia. Groups 1,2, and 4 were anesthetized with intraperitoneal pentobarbital $(65 \mathrm{mg} / \mathrm{kg})$, followed by i.v. fentanyl (5-10 $\mu \mathrm{g} / \mathrm{kg}$ ) when there were hemodynamic responses to surgical stimulation. Ventilation was maintained with a small animal ventilator (model 665, Harvard Apparatus Respirator, South Natick, MA) at a rate of $20-30$ breaths per minute, and a tidal volume of $10-15 \mathrm{~mL} / \mathrm{kg}$ through a tracheostomy. Preasphyxia arterial oxygen saturations were maintained $>90 \%$ with $0.21-$ 0.30 fractional inspired oxygen. Continuous end-tidal $\mathrm{CO}_{2}$ monitoring was used to maintain arterial $\mathrm{CO}_{2}$ tension at 35-45 $\mathrm{mm} \mathrm{Hg}$. Heparinized saline filled catheters were advanced into the thoracic aorta and thoracic inferior vena cava from bilateral femoral arteries and veins for continuous pressure monitoring, arterial blood sampling, and i.v. fluid administration. A brass screw was inserted into the skull to approximate the dural surface, $5 \mathrm{~mm}$ anterior to the coronal suture and $5 \mathrm{~mm}$ to the left of the sagittal suture for recording cortical SEP. A needle electrode was positioned midline within the exposed $\mathrm{C} 2-\mathrm{C} 3$ intervertebral space posteriorly to record evoked potentials and to assure intact peripheral nerve transmission during stimulation. Stimulus needle electrodes were placed $5 \mathrm{~mm}$ apart directly into a branch of the exposed right brachial plexus. The reference and ground needle electrodes were placed in the snout and tongue, respectively. Temperature was controlled by a water-circulating heating pad and a heat lamp to maintain a rectal temperature of $38-39^{\circ} \mathrm{C}$. After surgery, $30 \mathrm{~mL}$ of $2.5 \%$ dextrose in $0.45 \%$ normal saline were infused over $10 \mathrm{~min}$ to increase cardiac filling pressure and increase the likelihood of generating adequate coronary perfusion pressures for successful resuscitation during chest compression. The animals were paralyzed with pancuronium bromide $(1 \mathrm{mg}$ i.v.) before data collection. Additional pancuronium (1 mg) was administered if there was excessive muscle movement during the hourly foreleg stimulation when generating the SEP. Piglets were given at least $5 \mu \mathrm{g} / \mathrm{kg}$ of fentanyl every hour. If they began to move during the intervening period between pancuronium administration, an additional $5 \mu \mathrm{g} / \mathrm{kg}$ fentanyl was injected.

Piglets in group 3 were anesthetized with i.v. pentobarbital $(6-15 \mathrm{mg} / \mathrm{kg})$ and fentanyl $(50 \mu \mathrm{g} / \mathrm{kg})$ and then were immediately killed with intracardiac saturated potassium chloride solution to obtain baseline tissue water content values without prolonged anesthesia. No evoked potentials were obtained in group 3.

Experimental protocol. Seven minutes of complete asphyxia was performed by mechanical occlusion of the endotracheal tube. The piglets were resuscitated by resumption of mechanical ventilation at a rate of 20 breaths per minute with an inspired fractional oxygen of 1.0 and a positive inspiratory pressure of $26-30 \mathrm{~cm} \mathrm{H}_{2} \mathrm{O}$. Epinephrine was infused as an i.v. bolus of $100 \mu \mathrm{g} / \mathrm{kg}$ followed by a $10 \mu \mathrm{g} / \mathrm{kg} / \mathrm{min}$ infusion (18). Sternal compressions by a pneumatic chest compressor (Thumper, Michigan Instruments, Grand Rapids, MI) were initiated within $30 \mathrm{~s}$ if no arterial pressure response occurred with ventilation and epinephrine alone. Compressions were delivered at pressures of $30-40 \mathrm{~N} / \mathrm{kg}$ body weight with a $30 \%$ duty cycle and a rate of 100 per minute. The chest compressor and ventilator were controlled by a microprocessor to interpose a breath after every fifth compression. The epinephrine infusion was weaned aggressively after successful resuscitation over 15-30 min if mean arterial blood pressure was maintained $>50 \mathrm{~mm} \mathrm{Hg}$. Group $2(n=7)$ was analyzed through $6 \mathrm{~h}$ after an identical surgical preparation but without asphyxia. The animals were then killed with an i.v. injection of potassium chloride.

Measurements. Arterial and venous pressures were recorded continuously from the intrathoracic aorta and intrathoracic inferior vena cava with Statham $23 \mathrm{Db}$ pressure transducers all referenced to the right atrium. In group 1, arterial blood sampling occurred at baseline, at $5 \mathrm{~min}$ of asphyxia, and 10 min postresuscitation, and then hourly up to $6 \mathrm{~h}$. In group 2, samples were obtained at baseline, then hourly for $6 \mathrm{~h}$. Blood samples were analyzed for blood gases and $\mathrm{pH}$ using a Radiometer ABL3 electrode and analyzer system (Copenhagen, Denmark); oxygen saturation and $\mathrm{Hb}$ levels using a Radiometer OSM3 Hemoximeter (Copenhagen, Denmark); glucose and lactate using a 2300 STAT Yellow Springs Instrument Co. (Yellow Springs, $\mathrm{OH}$ ). In group 3, a single peripheral venous blood sample was obtained to evaluate $\mathrm{Hb}$, lactate, $\mathrm{pH}$, and blood gases. In group 4, cerebral blood flow was measured by the radiolabeled microsphere technique, and cerebral $\mathrm{O}_{2}$ consumption was calculated using sagittal sinus $\mathrm{O}_{2}$ content measurements as previously described $(18,19)$.

SEP (Cadwell Quantum 84, Cadwell Laboratory, Kennewick, WA, and Nicolet Spirit Evoked Potential System, Nicolet Instrument Corp., Madison, WI) were measured as previously described $(5,6,20)$. Measurements were made simultaneously with blood sampling.

Brain water content was determined by measuring the difference between wet and dry weight (21). In an attempt to minimize changes in water content secondary to normal regional variation (22), all animals had brain samples obtained from the same locations bilaterally. Samples of cortical parietal gray matter, subcortical white matter, pons, and lateral cerebellum (each weighing $100-300 \mathrm{mg}$ ) were weighed on predried, preweighed aluminum foil to determine the wet weight using a high precision balance $(0.0001 \mathrm{~g}$ precision). Dry weight measurements occurred after $72 \mathrm{~h}$ of drying in a $100^{\circ} \mathrm{C}$ 
oven. Brain water content was determined as a percentage of total regional weight according to the formula:

$$
\text { water content }=\frac{\text { wet weight }- \text { dry weight }}{\text { wet weight }} \times 100 \%
$$

Statistical analysis. The percent brain water content between the three groups was analyzed by one-way analysis of variance, followed by the Newman-Keuls multiple range test if the $F$ test was significant. Somatosensory evoked potentials and physiologic parameters across time and between groups were analyzed by two-way analysis of variance with repeated measures, with significance tested across time by the NewmanKeuls test and between groups by $t$ tests. Changes in cerebral blood flow and $\mathrm{O}_{2}$ consumption after asphyxia in group 4 were determined by repeated measures analysis of variance and the Newman-Keuls test. Data are reported as mean \pm SEM. A $p$ value $\leq 0.05$ was considered significant.

\section{RESULTS}

Mean body weights in groups 1,2 , and 3 were $3.1 \pm 0.2,2.7$ \pm 0.3 , and $3.0 \pm 0.2 \mathrm{~kg}$, respectively, and were not different among groups. During asphyxia (group 1), all physiologic parameters except glucose were significantly different from baseline (Table 1). Mean arterial blood pressure decreased $60 \%$ from baseline to $36 \pm 3 \mathrm{~mm} \mathrm{Hg}$ (range $25-43 \mathrm{~mm} \mathrm{Hg}$ ) and severe bradycardia occurred during asphyxia. Arterial $\mathrm{O}_{2}$ saturation at $5 \mathrm{~min}$ of asphyxia was $4.6 \pm 0.4 \%$. Arterial $\mathrm{O}_{2}$ saturation recovered during resuscitation, but recovery of ar- terial $\mathrm{pH}$ and lactate was delayed until $2 \mathrm{~h}$ postresuscitation. At 10 -min postresuscitation, arterial glucose concentration was transiently elevated to $9.9 \pm 2.3 \mathrm{mmol} / \mathrm{L}$

In the time control group (group 2), baseline $\mathrm{Hb}$ concentration, arterial pressure, and heart rate were lower than those in group 1 (Table 1). Baseline arterial lactate concentration was also slightly elevated in group 2. However, intergroup differences lost statistical significance over time as a result of increases in $\mathrm{Hb}$ concentration and heart rate in both groups, a decrease in arterial pressure in group 1, and a decrease in lactate concentration in group 2 . None of the physiologic parameters were different between groups at $6 \mathrm{~h}$ when water content was measured.

No increase in brain water content was found in any of the four regions measured at $6 \mathrm{~h}$ after $7 \mathrm{~min}$ of complete asphyxia when compared with the two control groups (Fig. 1). There was no difference in water content between group 2 with prolonged anesthesia and group 3 with a short anesthesia duration and no surgery.

The SEP amplitude was isoelectric during asphyxia and partially recovered during $6 \mathrm{~h}$ of reoxygenation (Fig. 2). Two animals in group 1 had SEP recovery $>92 \%$ by $6 \mathrm{~h}$. In the remaining five animals, mean recovery was $32 \%$ of baseline. In group 1 as a whole, SEP amplitude recovered to $50 \pm 13 \%$ of baseline (Fig. 3). In group 2, the SEP amplitude changed with time and increased to $71 \%$ above baseline. There were significant differences in SEP amplitude between groups 1 and 2 over time (Fig. 3). In group 1, latency to the first positive wave

Table 1. Physiologic variables in group 1 (asphyxia) before, during, and 1, 2, and 6 h after asphyxia, and in group 2 (time control)

\begin{tabular}{|c|c|c|c|c|c|}
\hline Variable and group & Baseline & Asphyxia & $1 \mathrm{~h}$ & $2 \mathrm{~h}$ & $6 \mathrm{~h}$ \\
\hline \multicolumn{6}{|l|}{$\mathrm{pH}$} \\
\hline Group 1 & $7.42 \pm 0.01$ & $6.95 \pm 0.06^{*}$ & $7.31 \pm 0.04^{*}$ & $7.38 \pm 0.02$ & $7.37 \pm 0.02$ \\
\hline Group 2 & $7.42 \pm 0.02$ & & $7.45 \pm 0.02 \dagger$ & $7.43 \pm 0.02 \dagger$ & $7.42 \pm 0.02$ \\
\hline \multicolumn{6}{|l|}{$\mathrm{PaCO}_{2}(\mathrm{kPa})$} \\
\hline Group 1 & $5.0 \pm 0.2$ & $14.3 \pm 1.2^{*}$ & $4.9 \pm 0.3$ & $5.1 \pm 0.1$ & $5.3 \pm 0.1$ \\
\hline Group 2 & $5.0 \pm 0.1$ & & $4.7 \pm 0.2$ & $5.1 \pm 0.1$ & $5.2 \pm 0.2$ \\
\hline \multicolumn{6}{|l|}{$\mathrm{PaO}_{2}(\mathrm{kPa})$} \\
\hline Group 1 & $14.2 \pm 2.7$ & $1.0 \pm 0.3^{*}$ & $27.4 \pm 3.4^{*}$ & $19.5 \pm 2.7$ & $16.1 \pm 1.3$ \\
\hline Group 2 & $12.7 \pm 1.2$ & & $12.4 \pm 0.9 \dagger$ & $14.5 \pm 2.9$ & $12.6 \pm 2.1$ \\
\hline \multicolumn{6}{|l|}{$\mathrm{O}_{2}$ Saturation $(\%)$} \\
\hline Group 1 & $95 \pm 1$ & $5.0 \pm 0.4^{*}$ & $99 \pm 0.3$ & $97 \pm 1$ & $97 \pm 1$ \\
\hline Group 2 & $97 \pm 1$ & & $97 \pm 1 \dagger$ & $96 \pm 1$ & $95 \pm 1^{*}$ \\
\hline \multicolumn{6}{|l|}{$\mathrm{Hb}(\mathrm{g} / \mathrm{L})$} \\
\hline Group 1 & $100 \pm 8$ & $114 \pm 10^{*}$ & $100 \pm 8$ & $113 \pm 9 *$ & $115 \pm 10^{*}$ \\
\hline Group 2 & $75 \pm 7 \dagger$ & & $72 \pm 6 \dagger$ & $87 \pm 10^{*}$ & $90 \pm 9^{*}$ \\
\hline \multicolumn{6}{|l|}{ Lactate $(\mathrm{mmol} / \mathrm{L})$} \\
\hline Group 1 & $1.3 \pm 0.1$ & $6.1 \pm 0.9^{*}$ & $4.2 \pm 0.7^{*}$ & $2.2 \pm 0.3$ & $1.2 \pm 0.2$ \\
\hline Group 2 & $2.3 \pm 0.2 \dagger$ & $\cdots$ & $1.4 \pm 0.1^{*} \dagger$ & $1.2 \pm 0.2 * \dagger$ & $0.9 \pm 0.1^{*}$ \\
\hline \multicolumn{6}{|l|}{ Glucose $(\mathrm{mmol} / \mathrm{L})$} \\
\hline Group 1 & $5.4 \pm 0.5$ & $4.9 \pm 0.3$ & $7.6 \pm 1.1$ & $5.5 \pm 0.7$ & $4.3 \pm 0.5$ \\
\hline Group 2 & $7.0 \pm 0.7$ & & $4.5 \pm 0.5^{*} \dagger$ & $4.4 \pm 0.5^{*}$ & $3.9 \pm 0.6^{*}$ \\
\hline \multicolumn{6}{|c|}{ Mean arterial pressure $(\mathrm{mmHg})$} \\
\hline Group 1 & $93 \pm 5$ & $36 \pm 3^{*}$ & $84 \pm 8$ & $84 \pm 5$ & $60 \pm 10^{*}$ \\
\hline Group 2 & $75 \pm 5 \dagger$ & & $79 \pm 5$ & $74 \pm 5$ & $76 \pm 4$ \\
\hline \multicolumn{6}{|l|}{ Heart rate (beats/min) } \\
\hline Group 1 & $231 \pm 12$ & $63 \pm 8^{*}$ & $262 \pm 14^{*}$ & $260 \pm 15^{*}$ & $291 \pm 12^{*}$ \\
\hline Group 2 & $178 \pm 15 \dagger$ & & $192 \pm 13 \dagger$ & $203 \pm 13 \dagger$ & $261 \pm 9^{*}$ \\
\hline
\end{tabular}

All values are mean $\pm \operatorname{SEM}(n=7$ in each group).

* $p<0.05$ compared to baseline within same group.

$\dagger p<0.05$ between groups. 


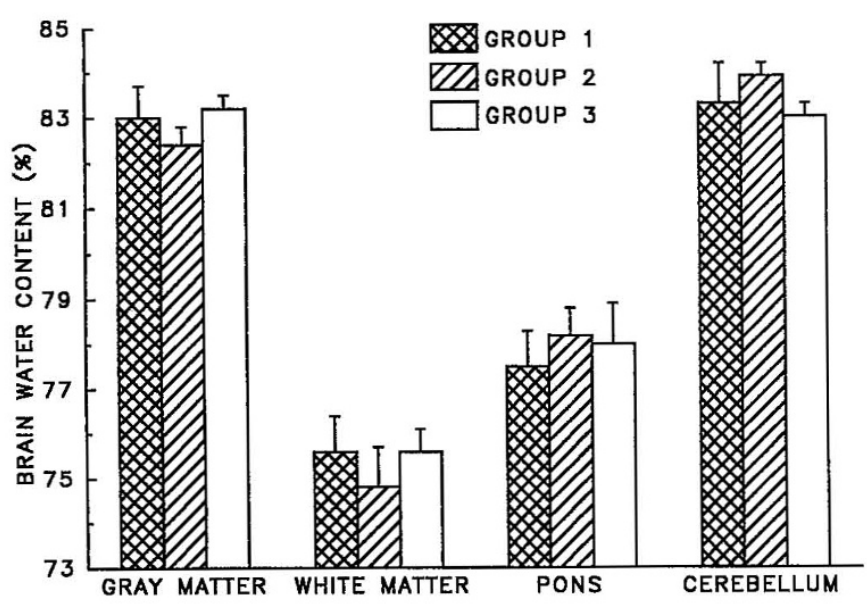

Figure 1. Brain water content as percent of total tissue weight measured in cortical gray matter, subcortical white matter, pons, and cerebellum in group 1 (asphyxia), group 2 (time control), and group 3 (brief anesthesia control). Values represent means \pm SEM.

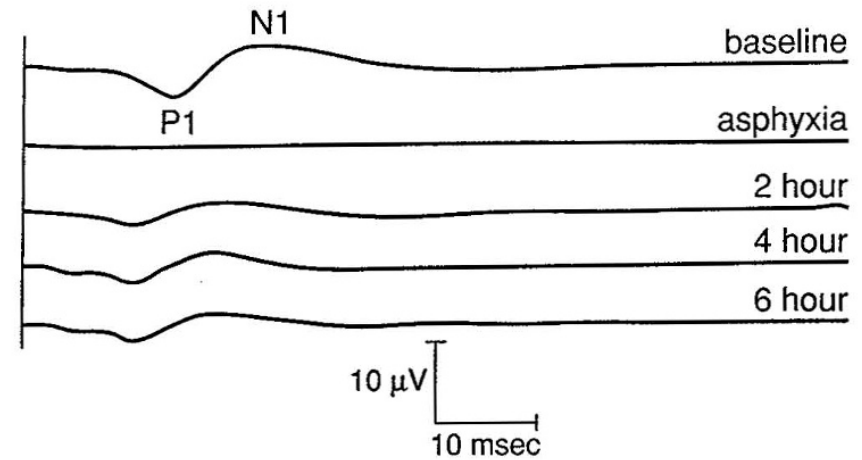

Figure 2. Examples of SEP cortical waveforms in a single asphyxiated piglet before, during, and 2, 4, and $6 \mathrm{~h}$ after resuscitation from a 7-min asphyxial insult. Each wave form represents the time-gated average of 128 stimulations at a rate of 2.9 per second with band pass filters set to 30 and $1500 \mathrm{KHz}$. SEP amplitude became isoelectric during asphyxia with a 52\% recovery by $6 \mathrm{~h}$ in this piglet. Amplitude is measured from the first positive deflection $(P l)$ to peak negative deflection $(\mathrm{NI})$ of the primary cortical wave complex. Latencies of P1 and N1 decreased after asphyxia, indicative of injury to slow conducting pathways.

(P1) decreased from $16.6 \pm 1.2$ to $13.6 \pm 0.6 \mathrm{~ms}$, and latency to the first negative wave $(\mathrm{N} 1)$ decreased from $26.1 \pm 2.1$ to $21.9 \pm 1.2 \mathrm{~ms}$. Latency to P1 was unchanged in the time control group 2 (18.6 \pm 0.7 to $17.5 \pm 0.6 \mathrm{~ms})$, but latency to $\mathrm{N} 1$ decreased from $28.5 \pm 1.3$ to $25.6 \pm 1.2 \mathrm{~ms}$. Latency to the wave recorded over the spinal cord at the $\mathrm{C} 2-\mathrm{C} 3$ interspace was unchanged in both group $1(3.90 \pm 0.23$ to $4.27 \pm 0.17 \mathrm{~ms})$ and group $2(4.24 \pm 0.27$ to $3.97 \pm 0.28 \mathrm{~ms})$.

In group 4 , cerebral blood flow increased $10 \mathrm{~min}$ after resuscitation and returned to baseline at 1 and $2 \mathrm{~h}$ (Table 2). Cerebral $\mathrm{O}_{2}$ consumption also recovered to baseline levels.

\section{DISCUSSION}

The major finding of this study is that brain water content did not increase at $6 \mathrm{~h}$ after $7 \mathrm{~min}$ of complete asphyxia in the immature piglet, even though electrophysiologic function remained significantly depressed from baseline. Persistent depression of SEP $6 \mathrm{~h}$ after an asphyxial insult is therefore not likely to be related to cerebral edema.

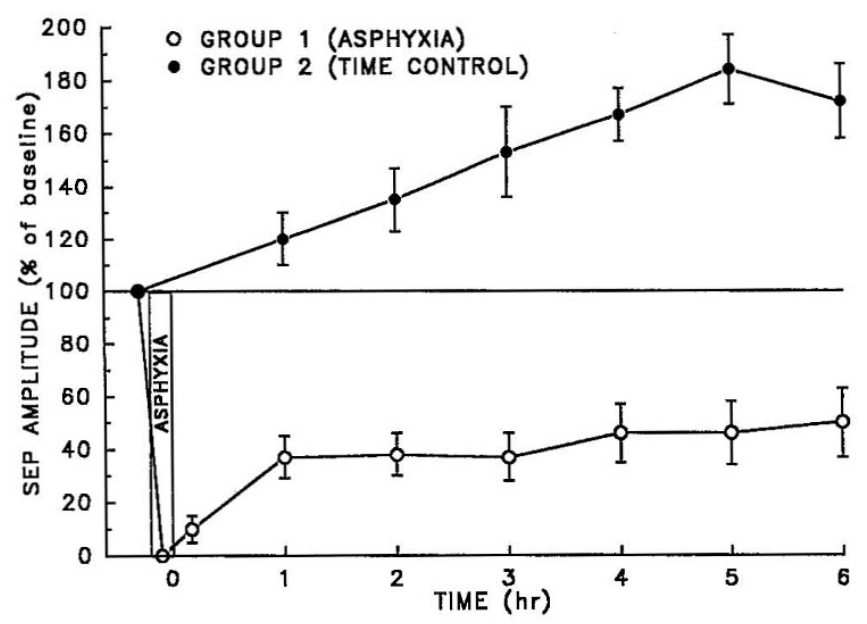

Figure 3. SEP amplitude as a percent of baseline during asphyxia, $10 \mathrm{~min}$, and 1-6 h after asphyxia in group 1 (asphyxia) and 1-6 $\mathrm{h}$ from control in group 2 (time control). Values between groups was significantly different at all points beyond baseline.

Table 2. Cerebral blood flow and $\mathrm{O}_{2}$ consumption before and after asphyxia (group 4)

\begin{tabular}{ccccc} 
& & \multicolumn{3}{c}{ Time after resuscitation (min) } \\
\cline { 3 - 5 } Measurement & Baseline & 10 & 60 & 120 \\
\hline $\begin{array}{c}\text { Cerebral blood flow } \\
\left(\mathrm{mL} \cdot \mathrm{min}^{-1} \cdot 100 \mathrm{~g}^{-1}\right)\end{array}$ & $54 \pm 5$ & $89 \pm 6^{*}$ & $56 \pm 8$ & $59 \pm 12$ \\
$\begin{array}{c}\text { Cerebral } \mathrm{O}_{2} \text { consumption } \\
\left(\mu \mathrm{mol} \cdot \mathrm{min}^{-1} \cdot 100 \mathrm{~g}^{-1}\right)\end{array}$ & $109 \pm 16$ & $63 \pm 18$ & $132 \pm 32$ & $124 \pm 29$ \\
\hline $\begin{array}{l}\text { Values are means } \pm \text { SEM }(n=7) . \\
* p<0.05 \text { from baseline. }\end{array}$ & & & \\
&
\end{tabular}

The immature piglet was felt to be an appropriate model for this study because of previous use in studies involving pediatric cardiopulmonary resuscitation $(19,23,24)$ and in studies examining cerebral blood flow, cerebral lipid peroxidation, and $\mathrm{Na}^{+}, \mathrm{K}^{+}$-ATPase loss after asphyxia (25-28). In addition, the 1- to 6-d age precedes the period of peak myelination in pig brain (29), thereby approximating a human newborn. In prior studies of asphyxia in immature piglets, the length of asphyxia often was determined as the time required to achieve a predetermined reduction in heart rate or blood pressure, which generally varied from 2 to $7 \mathrm{~min}(25-28)$. In preliminary studies in our laboratory, we found that heart rate and mean arterial blood pressure responses to brief asphyxia in immature piglets were too variable to achieve a consistent degree of asphyxia. After $7 \mathrm{~min}$ of asphyxia, however, all piglets had a mean arterial pressure $\leq 45 \mathrm{~mm} \mathrm{Hg}$. Therefore we chose a standard time of $7 \mathrm{~min}$ of asphyxia so that we would produce a consistent cerebral insult but still allow for at least a $75 \%$ successful resuscitation rate. The dose of epinephrine chosen in this study has been shown to improve myocardial and cerebral blood flow during CPR in immature piglets $(18,30)$. In addition, epinephrine does not appear to have central effects that might improve SEP independent of improving cerebral blood flow $(20,31)$.

Cerebral edema is usually described as either cytotoxic or vasogenic to refer to two different mechanisms. Hypoxia may cause cytotoxic edema due to cellular injury with dysfunction of cell membrane ionic pumps. Vasogenic edema results from 
disruption of the blood-brain barrier, previously demonstrated in 2- to 3-wk-old piglets $4 \mathrm{~h}$ after resuscitation from an 8-min fibrillatory arrest (32). Therefore after asphyxia, both cytotoxic and vasogenic edema could have been anticipated. Stonestreet et al. (33) studied newborn piglets submitted to $1 \mathrm{~h}$ of hypoxia/ hypercapnia and $20 \mathrm{~min}$ of hypovolemic hypotension and saw no evidence of cerebral edema or increased blood-brain barrier permeability at $40 \mathrm{~min}$ or $24 \mathrm{~h}$ after resuscitation. That study supports our findings although it differs from the current study in the type of insult and the use of homogenized whole brain for analysis of water content.

The increase in cerebral blood flow that we observed at 10 min of reoxygenation and return toward baseline at $60 \mathrm{~min}$ are consistent with results from other laboratories $(34,35)$. We also observed recovery of cerebral $\mathrm{O}_{2}$ consumption after $7 \mathrm{~min}$ of asphyxia in piglets. This finding differs from the $25 \%$ reduction in cerebral $\mathrm{O}_{2}$ consumption observed after 60 -min asphyxia in lambs $(36,37)$. Because the lambs were subjected to $2 \mathrm{~h}$ of gradually increasing severity of asphyxia, this difference in recovery of $\mathrm{O}_{2}$ consumption is probably attributable to the more prolonged asphyxic insult in lambs.

Even with the more prolonged insult in lambs, no significant increase in cerebral water content was observed (38). In contrast, increased water content occurred after $3 \mathrm{~h}$ of hypoxia/ ischemia in 7-d-old rats (2). Thus, edema formation may require a more prolonged and severe insult. In addition, the 7-d-old rat brain is less mature than that of newborn lamb and pig and has higher water content $(88 \%)$ than that of lamb $(83 \%)$ and pig $(83 \%)$. Resolution of ischemic cell swelling may be less effective in the more immature brain with normally higher water content.

Because SEP amplitude remained depressed through $6 \mathrm{~h}$ of reoxygenation without evidence of edema in cortical gray matter or subcortical white matter, other explanations must be considered for the depressed SEP amplitude. First, in mature brain, ischemic neuronal injury without pan-cellular necrosis is thought to depend on excitatory neurotransmitter receptor activation $(39,40)$. Excitotoxic injury may be limited to dendritic processes and may not have a significant impact on overall tissue water content. However, damage to a sufficient number of dendritic processes could reduce the number of cortical generators detected in the primary cortical wave complex of the SEP.

Second, in some experimental models of global and focal ischemia in mature brain, loss of SEP correlated with reduction in blood flow, high energy phosphates and edema in subcortical white matter tracts rather than in gray matter (7-11). Perinatal models of asphyxia often show histologic changes in white matter $(41,42)$. Thus a second possible explanation for our results is that asphyxia causes electrophysiologic dysfunction of white matter tracts subserving the somatosensory pathway, but that the intensity of the injury is not sufficient to cause significant white matter edema.

A third possibility is that neurotransmission was impaired in peripheral nerve, spinal cord or thalamic nuclei. However, evoked potentials recorded at the second cervical vertebrae recovered after asphyxia, thereby indicating intact peripheral and spinal neurotransmission. Edema was not evident in pons through which spinothalamic sensory fibers pass. Therefore, it is likely that spinothalamic neurotransmission was also intact. However, our data do not exclude impaired synaptic transmission within the thalamus.

We found that $7 \mathrm{~min}$ of asphyxia was associated with partial recovery of SEP but full recovery of cerebral $\mathrm{O}_{2}$ consumption. These results are similar to the 55\% recovery of SEP and full recovery of $\mathrm{O}_{2}$ consumption obtained in 1-2-wk-old piglets after $10 \mathrm{~min}$ of complete ischemia (17). In mature pigs and dogs, ischemia of short duration also results in partial recovery of SEP and full recovery of global cerebral $\mathrm{O}_{2}$ consumption, whereas ischemia of long duration results in further depression of SEP recovery and partial recovery of $\mathrm{O}_{2}$ consumption (13, $16,17)$. Thus, there appears to be two components of impaired SEP recovery: one component associated with brief ischemia that depends on previous reductions in metabolism, but does not immediately recover when metabolism recovers, and a second component associated with prolonged ischemia in which sustained metabolic impairment results in further decrements in SEP. Alternatively, brief ischemic insults may cause reduced metabolism selectively in somatosensory cortex that is too small to be detected by global measurements of cerebral $\mathrm{O}_{2}$ consumption. Furthermore, full expression of the synchronized evoked response with maximum peripheral nerve recruitment may require transient increases in metabolism that cannot be adequately met in postasphyxic neurons.

In time controls, latency of the N1 wave decreased and the P1 N1 amplitude increased. Anesthesia was induced with pentobarbital and maintained with fentanyl. Because pentobarbital increases latency and decreases amplitude (43), SEP changes in our time control group were probably due to time-dependent clearance of pentobarbital from the brain. Time-dependent increases in heart rate in the control group are also consistent with pentobarbital clearance. In postasphyxic piglets, decreased amplitude was associated with decreased latency of both P1 and N1 waves. Pentobarbital clearance probably contributed to the decrease in latency. In addition, asphyxia may have selectively injured slow conducting pathways involving additional synapses or small, nonmedullated axons, and thereby cause a decrease in latency. Because the P1 wave is thought to arise from far-field, subcortical generators, the decrease in P1 latency may reflect injury to thalamic pathways with slow conduction times.

There were differences in baseline levels of arterial $\mathrm{Hb}$ and lactate concentrations, mean arterial pressure, and heart rate between the time control and asphyxic groups. Because anesthesia and surgical procedures were similar between groups, these baseline differences appeared to occur by chance and represent either normal biologic variability or variability in response to anesthesia, surgical stress, and fluid administration. Fluid administration was used to increase cardiac filling pressure and to improve the likelihood of successful resuscitation and may have caused hemodilution that eventually resolved and caused time-dependent increases in $\mathrm{Hb}$ concentration. Stability of arterial blood pressure and $\mathrm{pH}$ in the control group over a 6-h period supports the explanation that the timedependent increases in heart rate and SEP amplitude are due to 
pentobarbital clearance rather than physiologic instability in the preparation.

In summary, our data indicate that a 7-min period of complete asphyxia in 1- to 6-d-old piglets results in complete loss of neurotransmission in the forelimb somatosensory pathway with incomplete recovery at $6 \mathrm{~h}$ of reoxygenation and that this incomplete recovery was not associated with gross edema in cortical gray matter or subcortical white matter.

Acknowledgments. The authors are grateful to John Skully for his fine technical support and to Lisa DeLoriers and Loretta Hook for their excellent preparation of this manuscript.

\section{REFERENCES}

1. Barkovich AJ $1992 \mathrm{MR}$ and CT evaluation of profound neonatal and infantile asphyxia. Am J Neuroradiol 13:959-972

2. Mujsce DJ, Christensen MA, Vannucci RC 1990 Cerebral blood flow and edema in perinatal hypoxic-ischemic brain damage. Pediatr Res 27:450-453

3. Branston NM, Ladds A, Symon L, Wang AD 1984 Comparison of the effects of ischaemia on early components of the somatosensory evoked potential in brainstem, thalamus, and cerebral cortex. J Cereb Blood Flow Metab 4:68-81

4. Sato M, Pawlik G, Umbach C, Heiss W-D 1984 Comparative studies of regional CNS blood flow and evoked potentials in the cat. Stroke 15:97-101

5. Koehler RC, Backofen JE, McPherson RW, Jones Jr MD, Rogers MC, Traystman RJ 1989 Cerebral blood fiow and evoked potentials during Cushing response in sheep. Am J Physiol 256:H779-H788

6. McPherson RW, Zeger S, Traystman RJ 1986 Relationship of somatosensory evoked potentials and cerebral oxygen consumption during hypoxic hypoxia in dogs. Stroke $17: 30-36$

7. Lesnick JE, Michele JJ, Simeone FA, DeFeo S, Welsh FA 1984 Alteration of somatosensory evoked potentials in response to global ischemia. J Neurosurg 60:490-494

8. Lesnick JE, Coyer PE, Michele JJ, Welsh FA, Simeone FA 1986 Comparison of the somatosensory evoked potential and the direct cortical response following severe incomplete global ischemia: selective vulnerability of the white matter conduction pathways. Stroke 17:1247-1250

9. Graf R, Kataoka K, Rosner G, Heiss W-D 1986 Cortical deafferentation in cat focal ischemia: disturbance and recovery of sensory functions in cortical areas with different degrees of cerebral blood flow reduction. J Cereb Blood Flow Metab 6:566-573

10. Graf R, Kataoka K, Wakayama A, Rosner G, Hayakawa T, Heiss W-D 1990 Functional impairment due to white matter ischemia after middle cerebral artery occlusion in cats. Stroke 21:923-928

11. Kataoka K, Graf R, Rosner G, Heiss WD 1987 Experimental focal ischemia in cats: changes in multimodality evoked potentials as related to local cerebral blood flow and ischemic brain edema. Stroke 18:188-194

12. Matsumiya N, Koehler RC, Traystman RJ 1990 Consistency of cerebral blood flow and evoked potential alterations with reversible focal ischemia in cats. Stroke 21:908-916

13. Nishijima MK, Koehler RC, Hurn PD, Eleff SM, Norris S, Jacobus WE, Traystman RJ 1989 Postischemic recovery rate of cerebral ATP, phosphocreatine, $\mathrm{pH}$, and evoked potentials. Am J Physiol 257:H1860-H1870

14. Steinberg GK, Gelb AW, Lam AM, Manninen PH, Peerless SJ, Rassi Neto A, Floyd P 1986 Correlation between somatosensory evoked potentials and neuronal ischemic changes following middle cerebral artery occlusion. Stroke 17:1193-1197

15. Paschen W, Hossmann K-A, van den Kerckhoff W 1983 Regional assessment of energy-producing metabolism following prolonged complete ischemia of cat brain. J Cereb Blood Flow Metab 3:321-329

16. Ichord RN, Kirsch JR, Helfaer MA, Haun S, Traystman RJ 1991 Age-related differences in recovery of blood flow and metabolism after cerebral ischemia in swine. Stroke 22:626-634

17. Kirsch JR, Helfaer MA, Blizzard K, Toung TJK, Traystman RJ 1990 Age-related cerebrovascular response to global ischemia in pigs. Am J Physiol 259:H1551-H1558

18. Berkowitz ID, Gervais H, Schleien CL, Koehler RC, Dean JM, Traystman RJ 1991 Epinephrine dosage effects on cerebral and myocardial blood flow in an infant swine model of cardiopulmonary resuscitation. Anesthesiology 75:1041-1050
19. Schleien CL, Dean JM, Koehler RC, Michael JR, Chantarojanasiri T, Traystman RJ, Rogers MC 1986 Effect of epinephrine on cerebral and myocardial perfusion in an infant animal preparation of cardiopulmonary resuscitation. Circulation 73:809-817

20. Schleien CL, Koehler RC, Gervais HW, Berkowitz ID, Dean M, Michael JR, Rogers MC, Traystman RJ 1989 Organ blood flow and somatosensory-evoked potentials during and after cardiopulmonary resuscitation with epinephrine or phenylephrine. Circulation 79:1332-1342

21. Takahashi H, Koehler RC, Brusilow SW, Traystman RJ 1991 Inhibition of brain glutamine accumulation prevents cerebral edema in hyperammonemic rats. Am J Physiol 261:H825-H829

22. Shigeno T, Brock M, Shigeno S, Fritschka E, Cervós-Navarro J 1982 The determination of brain water content: microgravimetry versus drying-weighing method. J Neurosurg 57:99-107

23. Berkowitz ID, Chantarojanasiri T, Koehler RC, Schleien CL, Dean JM, Michael JR, Rogers MC, Traystman RJ 1989 Blood flow during cardiopulmonary resuscitation with simultaneous compression and ventilation in infant pigs. Pediatr Res 26:558564

24. Dean JM, Koehler RC, Schleien CL, Michael JR, Chantarojanasiri T, Rogers MC Traystman RJ 1987 Age-related changes in chest geometry during cardiopulmonary resuscitation. J Appl Physiol 62:2212-2219

25. Goplerud JM, Mishra OP, Delivoria-Papadopoulos M 1992 Brain cell membrane dysfunction following acute asphyxia in newborn piglets. Biol Neonate 61:33-41

26. Goplerud JM, Wagerle LC, Delivoria-Papadopoulos M 1989 Regional cerebral blood flow response during and after acute asphyxia in newborn piglets. J Appl Physiol 66:2827-2832

27. Laptook A, Stonestreet BS, Oh W 1982 The effects of different rates of plasmanate infusions upon brain blood flow after asphyxia and hypotension in newborn piglets. J Pediatr 100:791-796

28. Pourcyrous M, Leffler CW, Mirro R, Busija DW 1990 Brain superoxide anion generation during asphyxia and reventilation in newborn pigs. Pediatr Res 28:618621

29. Sheng HZ, Kerlero de Rosbo N, Carnegie PR, Bernard CCA 1989 Developmental study of myelin basic protein variants in various regions of pig nervous system. J Neurochem 52:736-740

30. Schoffstall JM, Spivey WH, Davidheiser S, Fuhs L, Kirkpatrick R Jr 1990 Endogenous and exogenous plasma catecholamine levels in cardiac arrest in swine. Resuscitation 19:241-251

31. Gervais HW, Schleien CL, Koehler RC, Berkowitz ID, Shaffner DH, Traystman RJ 1991 Effect of adrenergic drugs on cerebral blood flow, metabolism, and evoked potentials after delayed cardiopulmonary resuscitation in dogs. Stroke 22:1554-1561

32. Schleien CL, Koehler RC, Shaffner DH, Eberle B, Traystman RJ 1991 Blood-brain barrier disruption after cardiopulmonary resuscitation in immature swine. Stroke 22:477-483

33. Stonestreet BS, Burgess GH, Cserr HF 1992 Blood-brain barrier integrity and brain water and electrolytes during hypoxia/hypercapnia and hypotension in newborn piglets. Brain Res 590:263-270

34. McPhee AJ, Kotagal UR, Kleinman LI 1985 Cerebrovascular hemodynamics during and after recovery from acute asphyxia in the newborn dog. Pediatr Res 19:645-650

35. Pourcyrous M, Leffler C, Busija D 1990 Role of prostanoids in cerebrovascular responses to asphyxia and reventilation in newborn pigs. Am J Physiol 259:H662H667

36. Rosenberg AA, Murdaugh E 1990 The effect of blood glucose concentration on postasphyxia cerebral hemodynamics in newborn lambs. Pediatr Res 27:454-459

37. Rosenberg AA, Murdaugh E, White CW 1989 The role of oxygen free radicals in postasphyxia cerebral hypoperfusion in newborn lambs. Pediatr Res 26:215-219

38. Rosenberg AA 1988 Regulation of cerebral blood flow after asphyxia in neonatal lambs. Stroke 19:239-244

39. Siesjo BK 1992 Pathophysiology and treatment of focal cerebral ischemia. J Neurosurg 77:169-184

40. Inoue T, Kato H, Araki T, Kogure K 1992 Emphasized selective vulnerability after repeated nonlethal cerebral ischemic insults in rats. Stroke 23:739-745

41. Clapp III JF, Peress NS, Wesley M, Mann LI 1988 Brain damage after intermittent partial cord occlusion in the chronically instrumented fetal lamb. Am J Obstet Gynecol 159:504-509

42. Wagner KR, Ting P, Westfall MV, Yamaguchi S, Bacher JD, Myers RE 1986 Brain metabolic correlates of hypoxic-ischemic cerebral necrosis in mid-gestational sheep fetuses: significance of hypotension. J Cereb Blood Flow Metab 6:425-434

43. Sutton LN, Frewen T, Marsh R, Jaggi J, Bruce DA 1982 The effects of deep barbiturate coma on multimodality evoked potentials. J Neurosurg 57:178-185 